Article

\title{
An Income Model Using Historical Data, Power-Law Distributions and Monte Carlo Method for University Technology Transfer Offices
}

\author{
Ken Polasko ${ }^{1}$, Pedro Ponce ${ }^{2, *}$ and Arturo Molina ${ }^{2}$ (D) \\ 1 IGF Consulting, 12090 E. Columbine Dr., Scottsdale, AZ 85259, USA; kenpolasko@mail.com \\ 2 Tecnologico de Monterrey, Writing Lab, TecLabs, Vicerrectoría de Investigación y Transferencia de Tecnología, \\ Monterrey 64849, NL, Mexico; armolina@tec.mx \\ * Correspondence: pedro.ponce@itesm.mx
}

check for

updates

Citation: Polasko, K.; Ponce, P.; Molina, A. An Income Model Using Historical Data, Power-Law

Distributions and Monte Carlo Method for University Technology Transfer Offices. Future Internet 2021, 13, 122. https://doi.org/10.3390/fi13 050122

Academic Editor: Luis Javier Garcia Villalba

Received: 12 March 2021

Accepted: 27 April 2021

Published: 6 May 2021

Publisher's Note: MDPI stays neutral with regard to jurisdictional claims in published maps and institutional affiliations.

Copyright: (c) 2021 by the authors. Licensee MDPI, Basel, Switzerland. This article is an open access article distributed under the terms and conditions of the Creative Commons Attribution (CC BY) license (https:/ / creativecommons.org/licenses/by/ $4.0 /)$.

\begin{abstract}
Engineering education pushes the creation of new technology to solve community problems. The process of technology transfer promotes educational innovation in universities, a vital process that can improve citizens' quality of life in cities and rural communities. As a result, university technology transfer offices (TTOs) have to create strategies that motivate students and researchers to generate technology. Thus, a primary challenge that TTOs face is to know and communicate the income potential compared to their much more predictable and limited expense budgets. Institutional budgeting for a TTO's growth would be simplified if the office were on a solid financial footing, i.e., breaking even or making a financial return. Many offices assume that income is unpredictable, that it is a lottery, luck, and more stakes in the fire improve the odds of hitting a winner, etc. These common assumptions or beliefs provide only a vague insight into how to move an intellectual property (IP) portfolio strategy forward. How can a TTO be assessed for quantitative value and not just be a cost center adding qualitative value? This paper illustrates the first steps to understanding how to project potential income versus a much more predictable expense budget, which would allow universities to improve their technology transfer strategy and results. As a result, TTOs would operate under a more sustainable IP portfolio strategy, promote educational innovation in universities, and generate a more significant community impact.
\end{abstract}

Keywords: TTO income modeling; TTO economics; TTO IP portfolio strategy; IP portfolio quality; educational innovation; higher education

\section{Introduction}

Moving from research projects to technological development is not always easy since some university-industry relationships are not sufficiently communicative about the research areas that the industries are investigating. Additionally, some universities are not inclined to deal with real problems. Only theoretical aspects are covered in engineering courses, so the students do not know the market needs and are not prepared to propose and implement a startup. Moreover, some universities' research centers do not seek industrial partners because their primary funding is governmental. New educational models, especially in engineering departments, include IP courses to promote technology transfer. Higher education requires TTOs that fund research projects that create new products. Ideally, TTOs should be involved in research projects from the beginning because they can strategize to bring attractive new products to the marketplace. Therefore, students and researchers must know the primary capabilities of their TTO and integrate them into the strategic plan of their research. This means that TTOs must have sustainable financial systems in the universities. It is impossible to develop and promote technology in the universities if the TTOs do not play a fundamental role in the organization. Besides, the TTO can provide students and researchers with intellectual property information when planning a funding strategy. 
On the other hand, universities receive significant public resources to fuel innovation via research, and they are under increasing pressure to measure and improve their impact on society. When federally sponsored research mechanisms support the capabilities of TTOs in universities, there are three main options [1]:

- Universities could market new inventions using internal funds.

- Universities could hire private companies that market the inventions.

- Universities could prepare students and researchers to improve the new technology and consider developing a startup business plan.

The TTOs in universities have a low commercialization rate; sometimes, this condition is attributed to the lack of adequate training staff and invention processing capacity [1]. Besides, the high-tech technology that could be created in universities does not have a particular market segment and, therefore, the commercialization process can be complicated. Since TTOs contribute to the universities' societal impact, TTOs have to improve their commercialization rates.

A TTO can encourage and facilitate the transfer of innovations primarily through patents, copyrights, licenses, and other agreements. The impact of these reverberates throughout the value chain for existing companies and startups. For example, every dollar invested in a new company or startup generates an additional 1.8 dollars of indirect and induced value [2].

From a university's internal perspective, most institutions would welcome a TTO that breaks even and is self-sustaining over the long haul. However, many typical TTO metrics, such as the number of invention disclosures and patents, have little impact or correlation with income. In general, the standards for invention disclosures are low, and the historical number of patents does not represent a measure of financial value. Many universities have rallied around their TTOs, much like one of their sports teams. Even if the office's budget has to be heavily supplemented year after year, there is public relations value, school spirit, and rankings that underlie the continuation of financial support.

As mentioned in [3], the technology portfolio is the core of all the business in a firm. One of the main goals is to decrement risk and increment business opportunities by managing a set of technologies, resources, and markets. It is also important to mention that there are other factors that OTTs in universities can follow. For instance, a university technology transfer office's goal could be to increment the social impact of technology and not focus only on licensing revenue. Nevertheless, the social and financial interests could not be aligned [3]. The technology transfer professionals in universities mentioned that the commercialization pressure linked with licensing revenue has been augmented in the last 15 years [4]. Additionally, it was presented in [5] that technology transfer offices that adjust the portfolio over their aspirations performance archive better results regarding the productivity of the technology transfer office.

The question of "value" generated for some TTOs tends to focus more on public perception regarding the volume of patents or various national and peer rankings. These conditions do not promote the transfer of innovation. The question of financial return seems to be a lower level "value" generator. Thus, little quantitative effort has been made to understand and improve the odds that a TTO will be self-sufficient. Technology transfer activities can also generate income called technical income, and this income is a valuable reference for assessing a TTO. The activities can be classified as technology trade, testing, consulting, etc. [6]. However, very little work has been performed to produce TTO income models, and long-term tracking of TTO income has yielded minimal insights. One of the first papers to explore financial returns identified artificial intelligence as a sweet spot in terms of income and patent volume [7]. Except for Professor Ponce's paper [7], little effort has been made to understand the underpinnings of income generated by TTOs. Understanding the financial performance of TTOs has been hampered by a lack of basic income generation models, leaving open the questions:

- Is it luck?

- Is it random? 
- Is it a lottery?

- Do more "irons in the fire" increase the chances of greater financial returns?

- Is there a characteristic statistical distribution?

If one could tease out an underlying probability distribution from historical income data, one could explore modeling income and strategies to improve a TTO's financial performance. Reviewing selected historical TTO income data yields statistical distributions similar to those underlying historical venture capital return, which can be used to model TTO income.

To gain insight into TTO IP portfolios' potential, we developed a model based on historical income, power-law distributions [8], and Monte Carlo techniques [9]. This model, primarily based on historical data, is the first step to understanding the income potential of TTOs and can help define and evaluate a portfolio's investment strategy. This model does not forecast future income but the statistical probability of income generation based on a TTO's historical results. This kind of modeling/simulation enables probabilistic assessment but not point predictions. Roughly speaking, the model does not predict next year's income or shorter time horizons; without a detailed cash flow history, estimating next year's income is highly unlikely to be an accurate or reliable prediction. However, this model can illustrate the portfolio's probability of returning future positive cash flows (or not).

\section{High-Risk and High-Reward Return Distributions}

Venture capital (VC) seed investing is similar to university technology commercialization: they are both early-stage and high-risk. A VC's portfolio valuation or return-oninvestment curve is exceptionally skewed, as illustrated in Figure 1 [10]. Most startups make zero return, some make a small return, and a few deliver very high or "home run" returns. As Peter Thiel stated, "actual [10] returns are incredibly skewed. The more a VC understands this skewed pattern, the better the VC." [11].

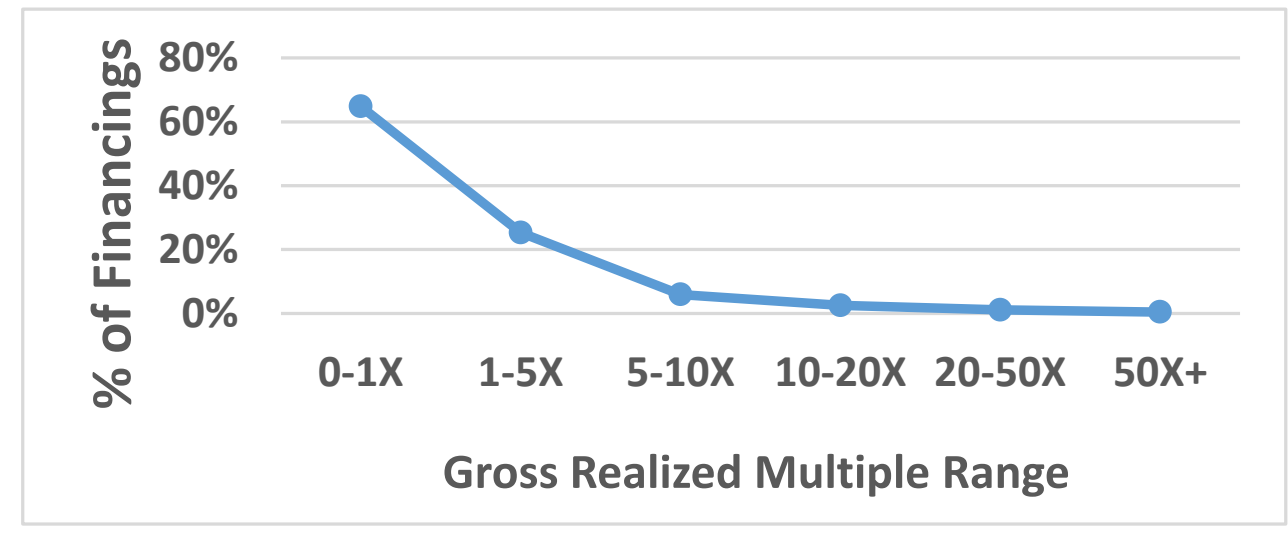

Figure 1. Typical distribution of venture capital returns.

The Association of University Technology Managers (AUTM) is an organization that collects and reports technology transfer data from universities and other institutions. An AUTM royalty income graph illustrates a similarly skewed distribution of venture capital returns (see Figure 2). A few institutions receive a significant income from their IP portfolio, but the vast majority do not break even. If one plots the AUTM income data on a log$\log$ scale, the data approximate a straight line, suggesting a power-law distribution (see Figure 3). 


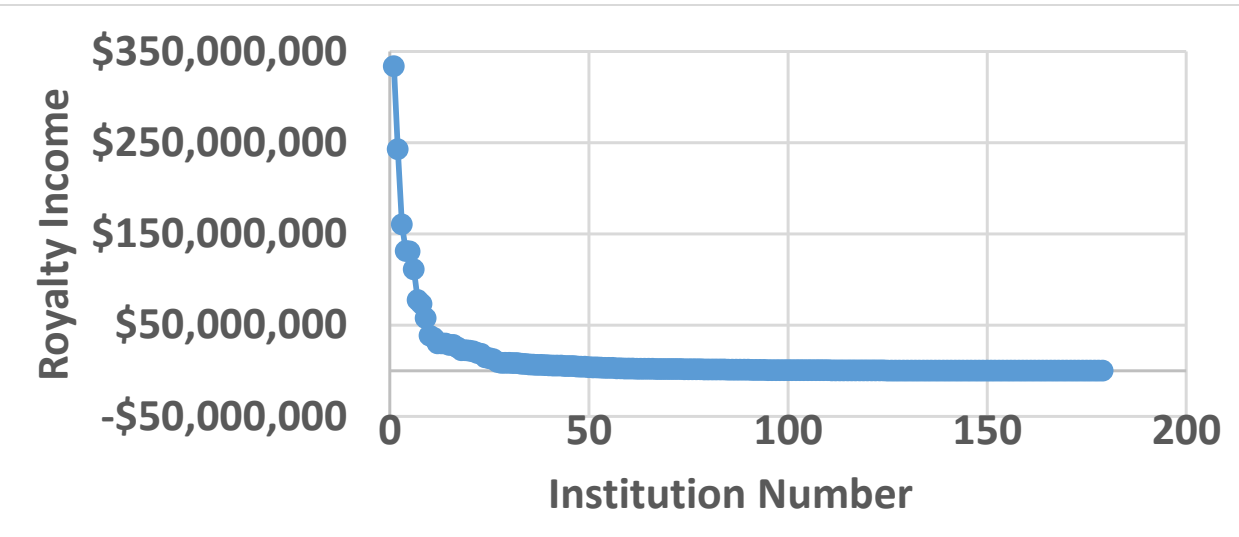

Figure 2. The fiscal year 2016 Association of University Technology Managers (AUTM) data.

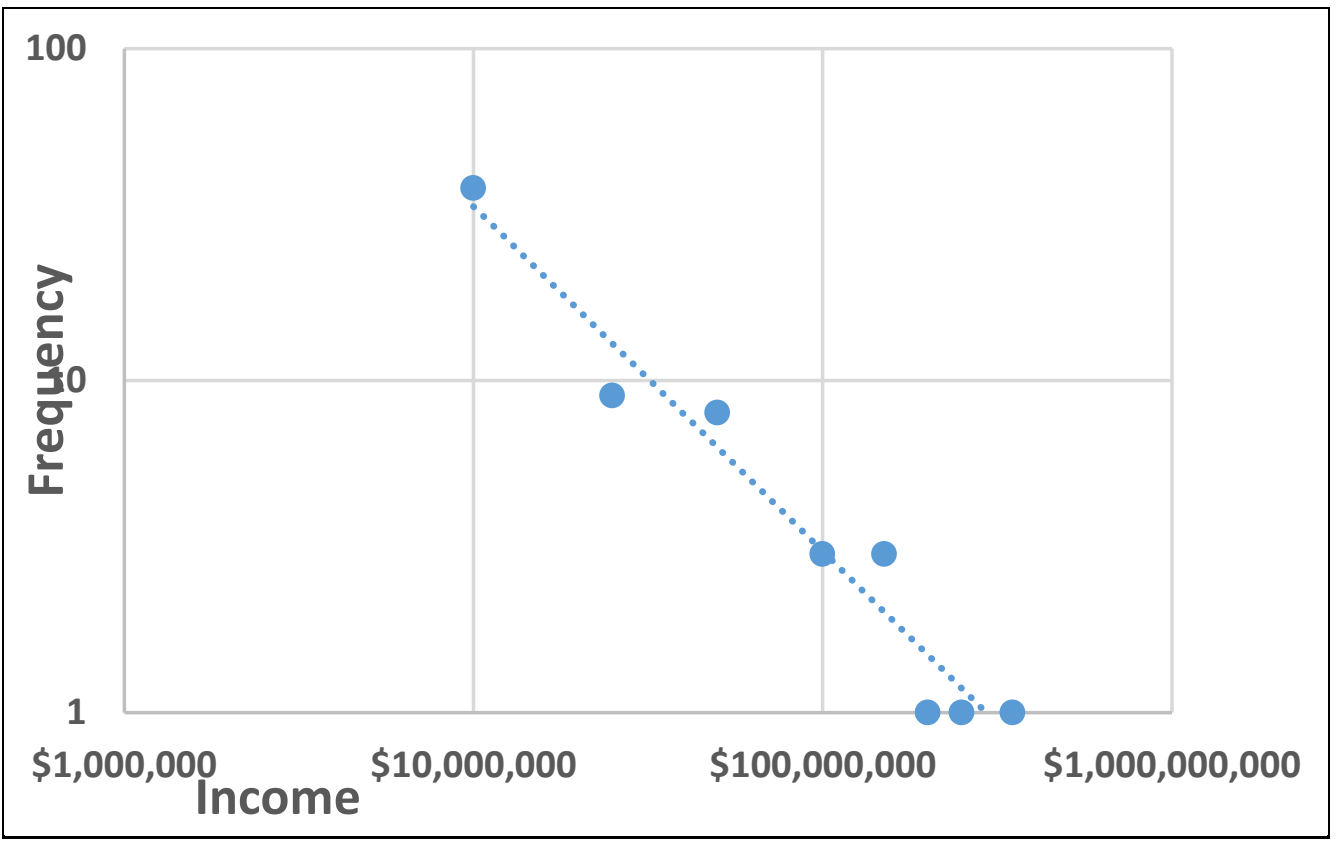

Figure 3. AUTM binned data plotted on a log-log scale.

Narrowing the data analyses from a collection of universities to individual universities, one finds similarly skewed income distributions. Figure 4 compares the income histories of two different universities, one with a medical school and the other without one. One set of data is from 1984-1998, and the other is from 2000-2017. The two schools' curves are similar, ignoring inflation. They resemble AUTM income and venture capital return curves: a few licenses generate a significant fraction of the total income, and most licenses generate minimal income. Like the AUTM data, if one plots the income data on a log-log scale, the data approximate a straight line, indicating a power-law distribution. The two universities' income data largely overlap; however, one school generated significant income, and the other lost money in most years. 


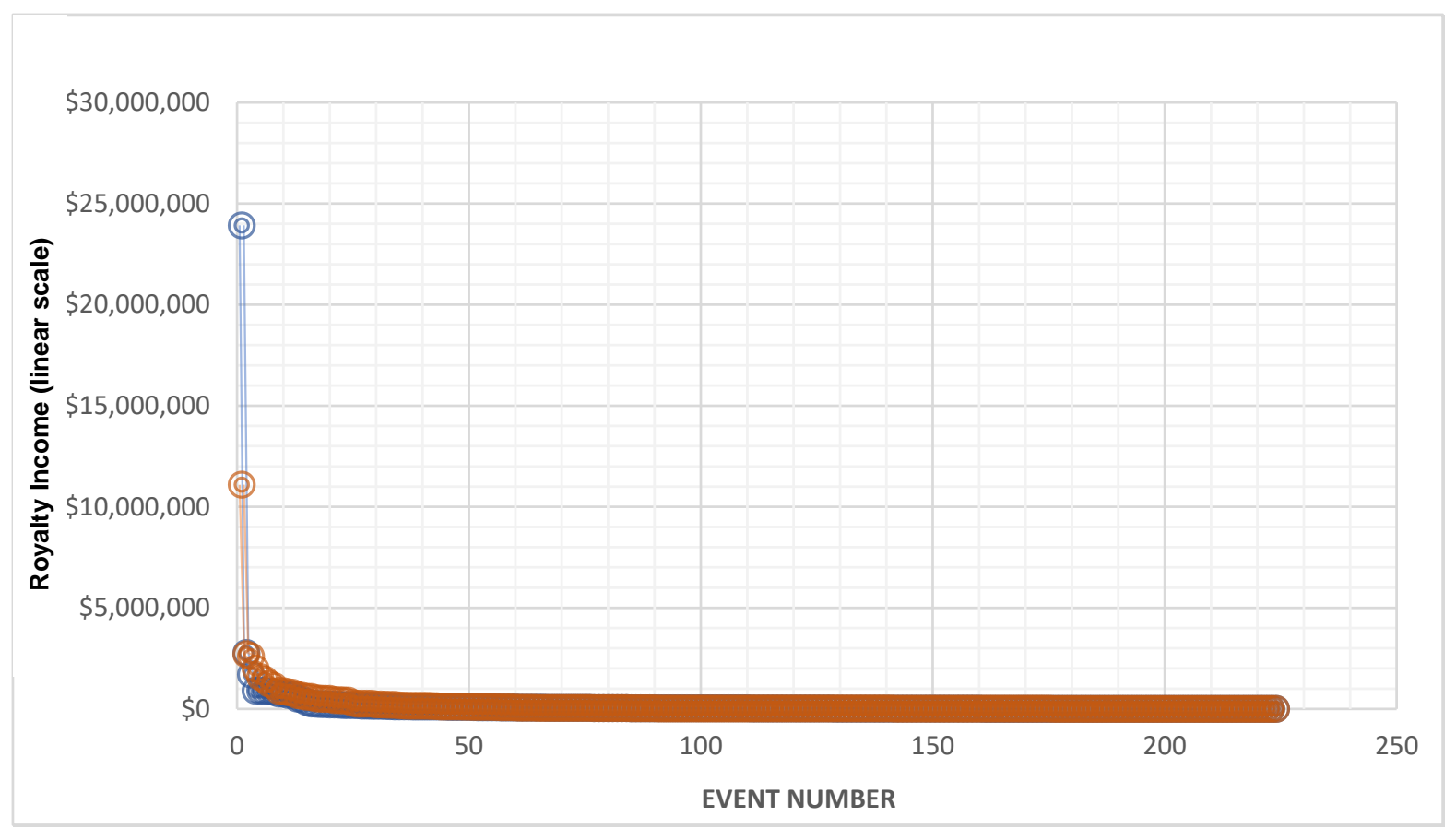

(a)

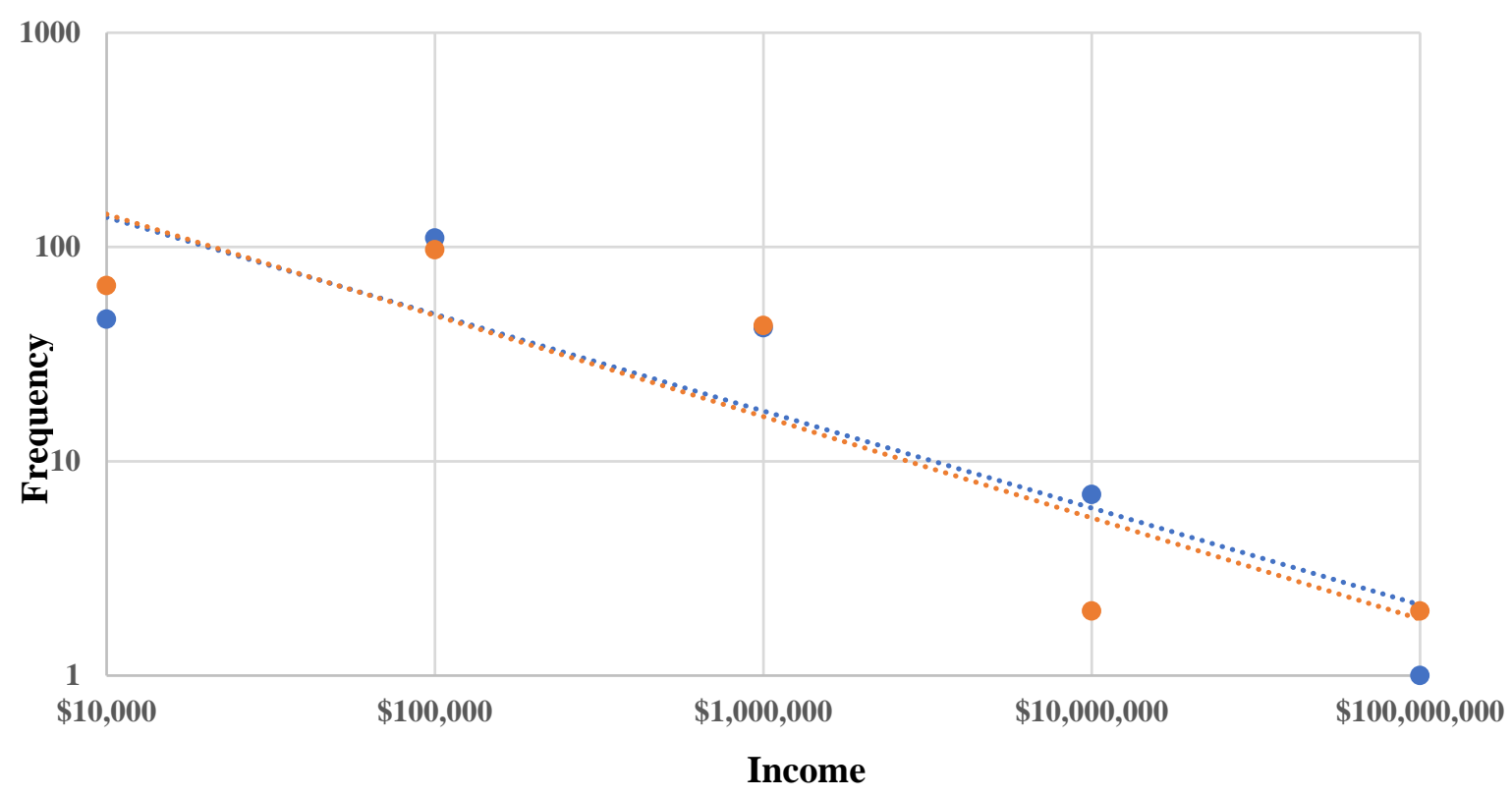

- University A

- University B

(b)

Figure 4. Two very different US research universities, yet, the two schools' royalty incomes are similar and can be modeled as power-law distributions. (a) Event number vs. royalty income; (b) income vs. frequency.

\section{Power-Law Distributions}

A power-law probability distribution function (PDF) is a very well-known technique [12] which can be defined as follows:

$$
\operatorname{PDF}(\times)=\mathrm{CX}^{-\alpha}
$$

where $\mathrm{C}$ is a normalizing constant. 
- When $\alpha>3$, the distribution has a finite mean and finite variance, similar to working with Gaussian-like distributions.

- When $2<\alpha \leq 3$, the distribution has a finite mean but undefined variance.

- When $\alpha \leq 2$, both the mean and variance are undefined. The implications in this region are unique.

In $[8,13,14]$, the information regarding the theory regarding power-law distribution is presented. Several computational programs contain specific functions that can be used for calculating the power-law distribution when a large amount of data is studied, such as [15].

Interestingly, most VC return-on-investment [16], AUTM income, and the two universities' income data presented above follow a power-law curve with an $\alpha$ range of 0.5 to 2.0. The lower the $\alpha$, the higher the chances of an extreme or "Black Swan" event [17].

Understanding the implications of power-law statistics requires a different thought process than more common Gaussian statistics [18]. The primary difference between a Gaussian and power-law driven statistic is the tail. So-called tail events are much more likely in a power-law versus a Gaussian-driven process. A Gaussian-driven process is much more familiar and widely analyzed via averages and standard deviations. A powerlaw-driven process is much less familiar to most, not as intuitive, and, in some cases, cannot even be characterized via averages and standard deviations. However, power-laws are common in business, nature, and economics [8]. For example, earthquakes can be modeled with power-law distributions. Many little earthquakes have minimal impact, while a few big ones have a significant impact-just as with TTO deals, where there are many small ones and a few big shakers/Black Swan events/unicorns.

From a financial modeling perspective, one important point is that this is only concerned with high-income events. Events that generate a minimal income are of little value since they contribute a small fraction of the overall return. A non-power-law distribution might better model them.

\section{Portfolio Modeling}

The makeup of a TTO's IP portfolio can be defined similarly to a VC's startup portfolio:

The majority of startups realize zero return $(0 \times, 50-60 \%)$, some break even or generate a minimal return $(1-10 \times, 30-40 \%)$, and a small number achieve a significant/power-law return on investment $(>10 \times, 5-10 \%)$.

To model a venture capital portfolio, the payoff structure from pooled data for 509 startups from 1995-2009 was used [19]. The makeup of a TTO's IP portfolio can be defined similarly to a VC's startup portfolio:

- Many startups "strike out" and return less than one times the investment $(<1 \times$ return, $63.1 \%)$,

- "Singles" break even or generate a minimal return (1-3× return, $19.6 \%)$,

- "Doubles" generate a good return (3-6x return, 9.2\%),

- "Triples" generate a very good return $(6-10 \times, 4.3 \%)$, and

- "Home runs" generate a large/power-law return on investment ( $>10 \times$ return, 3.7\%).

The academic portfolios in this study do not include patented technologies that generated zero income. This is an essential point since unlicensed technologies can comprise a high percentage of the patent portfolio. This will be discussed later in regard to how this might impact a TTO's ability to break even. It is essential to mention that the academic and venture portfolio returns are so similar in Figure 5. If the academic data set had included patented and unlicensed cases, the percentage distribution in the $<=1$ category would have been much more significant. To calculate the academic return, an estimate of the fully loaded cost of filing a patent was used. For example, if patent prosecution costs are USD 20,000 and approximately half of the TTO's budget is prosecution costs, then the fully loaded cost of filing is estimated to be USD 40,000. 


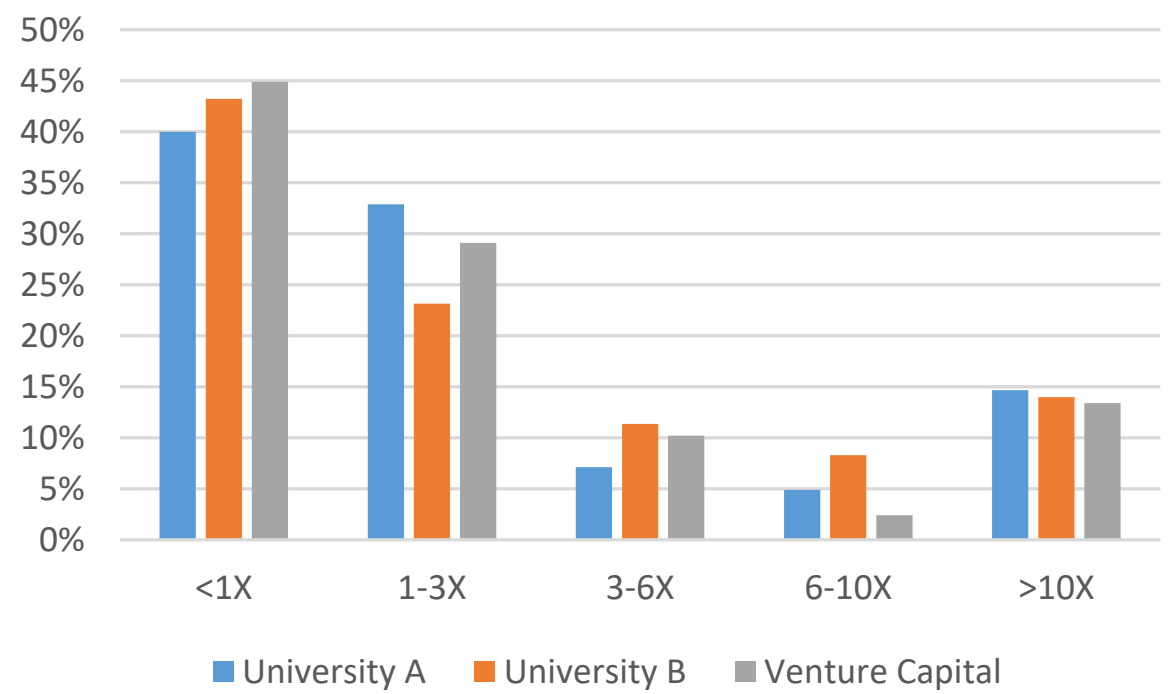

Figure 5. Make up different return categories for venture and two universities.

Once the return make-up of a portfolio was defined (e.g., 63.1\%, 19.6\%, 9.2\%, 4.3\%, and $3.7 \%$ ) and the "tail" or high-income part of the distribution $(>10 \times)$ was matched to a power-law distribution (e.g., $\alpha=2.0$ typical for a VC fund), then a Monte Carlo simulation of individual event returns $[20,21]$ was generated, see Figure 6 . For practical purposes, it was assumed that the power-law return distribution is limited to $10 \times$ through $150 \times$. The summation of 10,000 individual Monte Carlo simulation return events will make up the portfolio's total return.

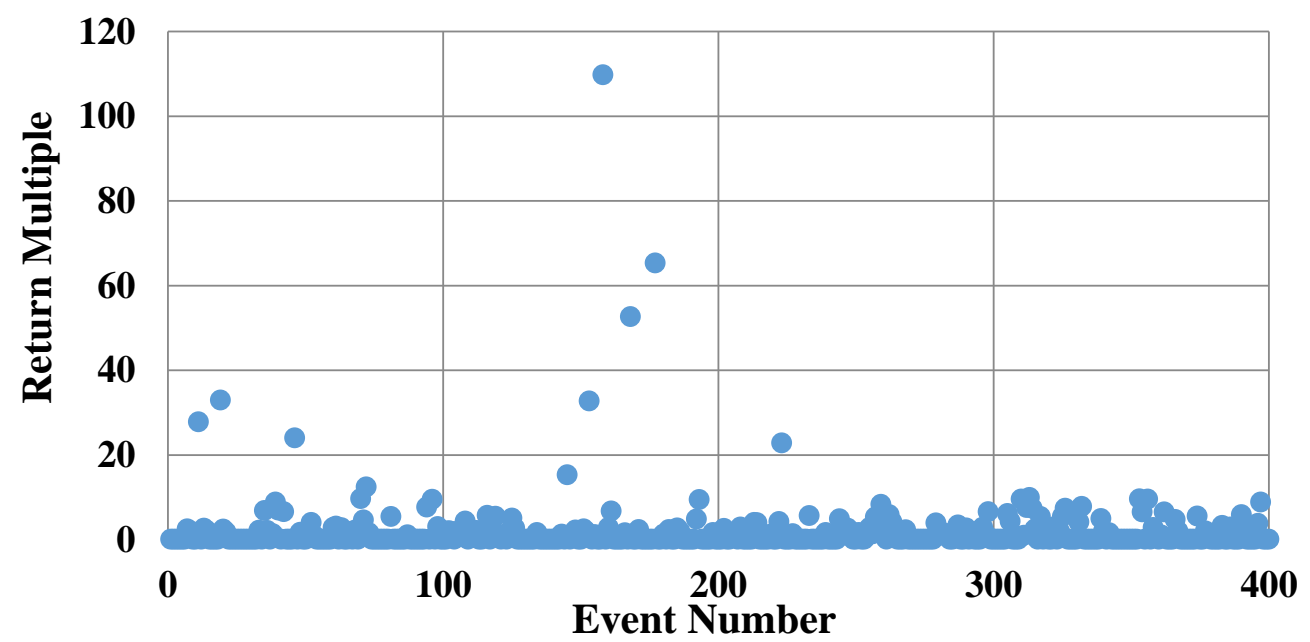

Figure 6. Monte Carlo simulation of 400 portfolio-driven events.

Figure 7 illustrates the impact that portfolio size has on the probability of achieving breakeven or a $2 \times, 3 \times$, and $5 \times$ return. In general, a more extensive portfolio is advantageous. A larger portfolio increases the likelihood of a power-law return or Black Swan event. For clarity, a more extensive portfolio means a more significant, fully vetted portfolio, not just a quantitative larger portfolio. All portfolio additions have met the same hurdle rates in terms of quality to be added to the portfolio. Adding low quality to a portfolio will, in general, be harmful to a portfolio's return. The reported return generated by this collection of 509 early-stage portfolio companies is reported to be $2.0 \times$, which is in agreement with the simulation trend out to a portfolio of 400 . 


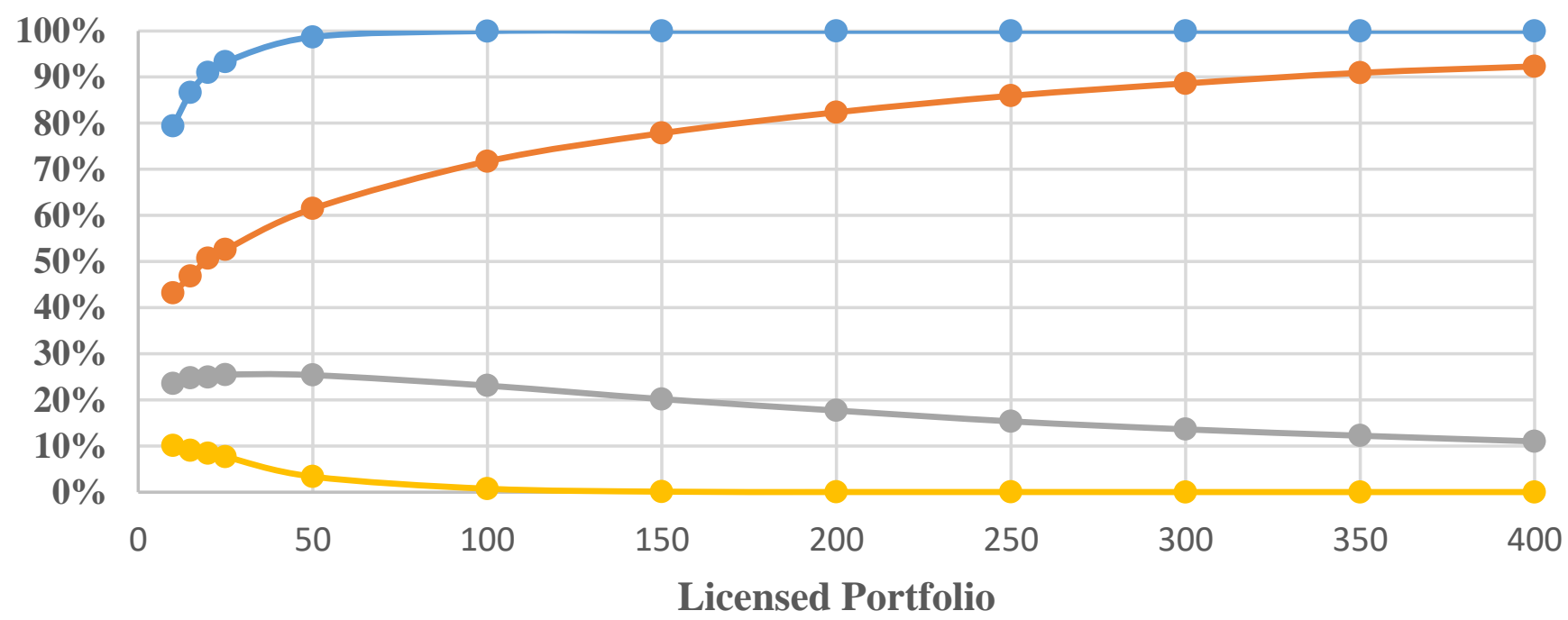

$\longrightarrow$ Breakeven $\longrightarrow>2 x \longrightarrow 3 x \longrightarrow 5 x$

Figure 7. Portfolio return probability after 10,000 Monte Carlo simulations.

Figure 8 illustrates the impact that portfolio quality has on a portfolio's probability of making a $2 \times$ or higher return. Reducing the number of power-law events will have a significant impact on the portfolio's potential total return. However, going to a lowerquality portfolio (power-law events occur at a $1 \%$ frequency), the portfolio breaks even, except for very small portfolio sizes. If all power-law events were eliminated, the average return is slightly over $1 \times$. This is why the portfolio breakeven is achieved even if there were no power-law returns. For this particular portfolio, there are enough singles, doubles, and triples to break even. Suppose it is estimated that $20 \%$ of a TTO's patented portfolio is licensed and the other $80 \%$ is not licensed; the model financials change radically. Assume that the licensed portfolio generates a return of $1 \times, 2 \times, 3 \times$, and $5 \times$, and the fully loaded cost of a patent investment is USD 40,000 - even with a high probability of a power-law or Black Swan event, it is difficult to reach breakeven due to the high cost of patenting a large percentage of nonperforming technologies.
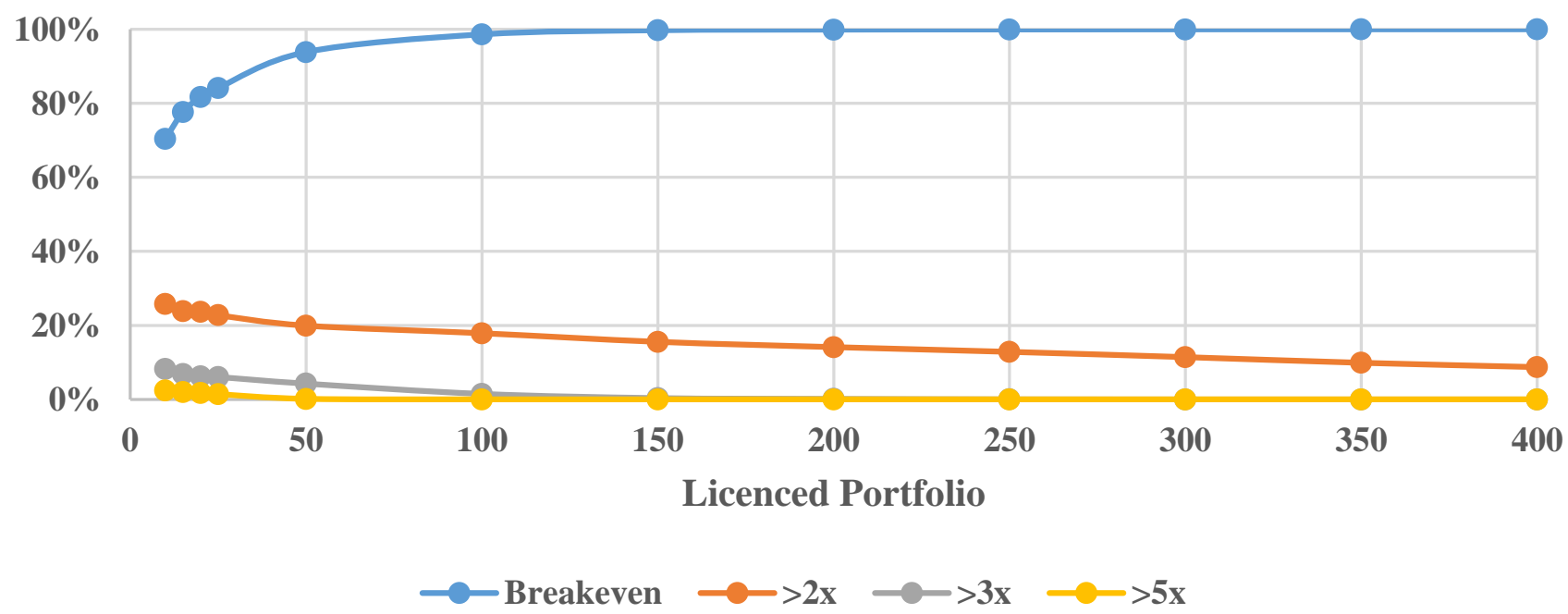

Figure 8. Impact of a lower quality portfolio: fewer power-law returns: $3.7>1.0 \%$.

This would be similar to a VC fund putting $80 \%$ of its fund into startups after having just reviewed the pitch deck and not fully vetted the opportunity. There is a common saying that one cannot pick winners (power-law or Black Swan innovations); however, it could be 
a significant number of patent filings that have a low probability of ever reaching just a breakeven point, let alone a Black Swan-like return. These are innovations that might be filed for political reasons, increasing university rankings, or just assuming that innovations are lottery tickets. The more you have, the higher your chances of finding a diamond in the rough. VCs' extensive efforts in vetting their investments would argue that the probability of these innovations making a significant return is more complex than just thinking of them as lottery tickets. Generating significant returns is not a lottery. All lottery tickets are the same, with the same odds of producing a winner-not so with IP assets. If a TTO invests in a large number of low-potential patent opportunities, then their costs may overshadow the relatively rare Black Swan event/s. A large multi-state Powerball Lottery can produce a return of several million times the cost of the winning ticket, but there is zero total return due to the much larger pool of losing tickets-especially if your lottery ticket costs USD $10,000 \mathrm{~s}$ each. The same goes for TTO portfolios; investing in potential high-return assets increases the quality of the portfolio and the chances of making a positive financial return.

There is a significant trade-off between resources spent on generating quantity metrics (invention disclosures, issued patents and patent rankings, etc.) versus resources spent on vetting high-quality IP portfolios that have the potential to realize a return on investment. This is why VC investors do such extensive filtering to find the companies that can become unicorns/Black Swans.

Figure 9 illustrates the challenges for generating returns greater than breakeven if the cost of the unlicensed portfolio and its impact on total return are considered. The challenges for universities are different than VCs that typically target a $3 \times$ fund return. For example, VC funds have the ability and resources to invest in future rounds to keep their equity position from being significantly diluted, and VCs assist with moving the company forward as active partners. Once a university license is completed, the TTO is more of a passive investor. It is clear that even with reasonable returns $(2 \times$ and $3 \times$ total portfolio returns), the cost for the unlicensed patent portfolio limits the total portfolio return.
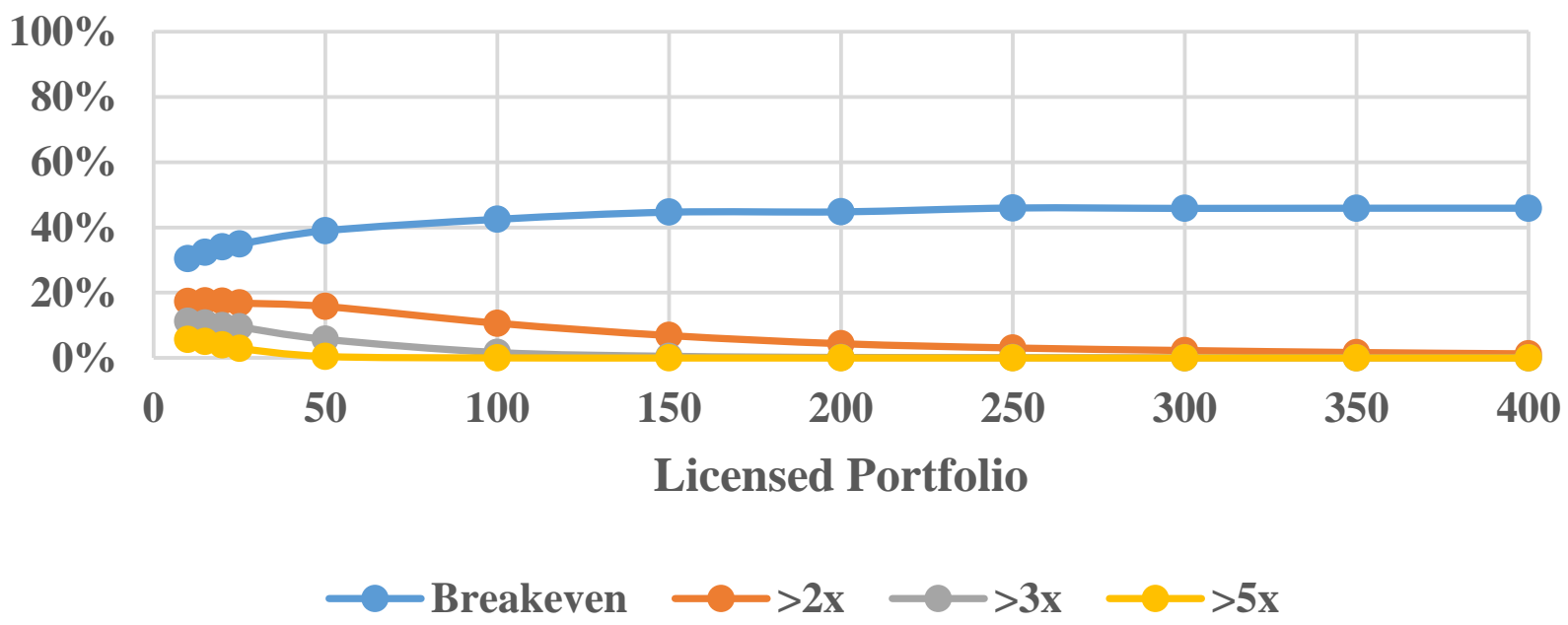

Figure 9. The challenge of breaking even when $20 \%$ of the patented portfolio is licensed, and the cost burden of the $80 \%$ unlicensed portfolio is included.

\section{Conclusions}

This paper shows how the historical data of technology transfer offices can be used for modeling the technology transfer office's portfolio income using the power-law probability distributions and Monte Carlo methods. Since financial conditions in technology transfer offices are a significant factor for assessing their financial performance, creating a model regarding the technology transfer office's portfolio becomes mandatory in most universities. 
Understanding the implications of power-law distributions can help TTOs estimate the likelihood of financial returns. This modeling approach reinforces the notion that it is tough to pick winners. If the IP selection process does not set a high enough bar, low-potential investments can outweigh the relatively rare winners.

However, there are not enough academic references to model this portfolio, and there is a lack of information about how to model it. This paper also presents how these two well-known methodologies, power law distribution and Monte Carlo, can be used to reach a portfolio income model. On the other hand, there are other factors that some universities include for evaluating their performance, such as impact in the community when technology transfer is done. Thus, this paper does not evaluate the complete performance of the technology transfer that can integrate several factors.

Author Contributions: Conceptualization, K.P. and P.P.; methodology, K.P. and P.P.; software, K.P.; validation, K.P.; formal analysis, K.P. and P.P.; investigation, K.P., P.P. and A.M.; resources, K.P. and P.P.; data curation, K.P.; writing-original draft preparation, K.P., P.P. and A.M.; writing-review and editing, K.P. and P.P.; visualization, K.P., P.P. and A.M.; supervision, K.P.; project administration, K.P., P.P. and A.M.; funding acquisition, P.P. All authors have read and agreed to the published version of the manuscript.

Funding: The authors would like to acknowledge the financial support of Writing Lab, Institute for the Future of Education, Tecnologico de Monterrey, Mexico, in the production of this work.

Data Availability Statement: Not applicable, the study does not report any data.

Acknowledgments: The authors would like to acknowledge the administrative support of Writing Lab, Institute for the Future of Education, Tecnologico de Monterrey, Mexico, in the production of this work.

Conflicts of Interest: The authors declare no conflict of interest.

\section{References}

1. Swamidass, P.M.; Vulasa, V. Why university inventions rarely produce income? Bottlenecks in university technology transfer. J. Technol. Transf. 2009, 34, 343-363. [CrossRef]

2. Madly, E.; Hoffman, D. The Economic Impact of Arizona Technology Enterprises (AzTE) and the ASU-Linked Companies It Has Enabled in 2016 and 2017, and Potential Future Economic Impacts of ASU-Linked Companies; L. William Seidman Research Institute: Tempe, AZ, USA, 2017.

3. Sadowski, M.; Roth, A. Technology leadership can pay off. Res. Technol. Manag. 1999, 42, 32-33. [CrossRef]

4. Bubela, T.M.; Caulfield, T. Role and reality: Technology transfer at Canadian universities. Trends Biotechnol. 2010, 28, 447-451. [CrossRef] [PubMed]

5. Lafuente, E.; Berbegal-Mirabent, J. Assessing the productivity of technology transfer offices: An analysis of the relevance of aspiration performance and portfolio complexity. J. Technol. Transf. 2019, 44, 778-801. [CrossRef]

6. Zhao, H.; Grier, D.A. Factors influencing technology transfer: The case of China. J. Technol. Transf. 1991, 16, 50-56. [CrossRef]

7. Ponce, P.; Molina, A.; Polasko, K. Efficient Operation in University Technology Transfer. Int. J. Adv. Res. Comput. Sci. Softw. Eng. 2013, 3, 1 .

8. Clauset, A.; Shalizi, C.R.; Newman, M.E.J. Power-lawn Distributions in Empirical Data. SIAM Rev. 2009, 51, 661-703. [CrossRef]

9. Weller, R.A.; Mendenhall, M.H.; Reed, R.A.; Schrimpf, R.D.; Warren, K.M.; Sierawski, B.D.; Massengill, L.W. Monte Carlo simulation of single event effects. IEEE Trans. Nucl. Sci. 2010, 57, 1726-1746. [CrossRef]

10. Levine, S. Venture Outcomes Are Even More Skewed Than You Think. VCAdventure. 12 August 2014. Available online: https://www.sethlevine.com/archives/2014/08/venture-outcomes-are-even-more-skewed-than-you-think.html (accessed on 27 April 2021).

11. Theil, P. Follow the Money. Stanford University. CS183: Startup, Spring, Class 7. 2012. Available online: https://followthemoney. stanford.edu/ (accessed on 27 April 2021).

12. Mandelbrot, B. New Methods of Statistical Economics Revisited: Short versus Long Tails and Gaussian versus Power-law Distributions. Econophysics 2009, 14, 55-65. [CrossRef]

13. Gabaix, X.; Gopikrishnan, P.; Plerou, V.; Stanley, H.E. A theory of power-law distributions in financial market fluctuations. Nature 2003, 423, 267-270. [CrossRef] [PubMed]

14. Mitzenmacher, M. A brief history of generative models for power law and lognormal distributions. Internet Math. 2004, 1, 226-251. [CrossRef]

15. Alstott, J.; Bullmore, E.; Plenz, D. Power-law: A Python package for analysis of heavy-tailed distributions. PLoS ONE 2014, 9 , e85777. 
16. Neumann, J. Power Laws in Venture Portfolio Constructions. Reactionwheel.net. 3 December 2017. Available online: http: / / reactionwheel.net/2017/12/power-laws-in-venture-portfolio-construction.html (accessed on 27 April 2021).

17. Korver, C. Picking winners is a myth, but the PowerLaw is not. Ventur. Cap. J. 2017, 1, 1.

18. Bak, P. How Nature Works; Springer Science+Business Media: New York, NY, USA, 1996.

19. Sahlman, W. Risk and Reward in Venture Capital; Harvard Business School Press: Cambridge, MA, USA, 2010.

20. Binder, K.; Heermann, D.; Roelofs, L.; Mallinckrodt, A.J.; McKay, S. Monte Carlo simulation in statistical physics. Comput. Phys. 1993, 7, 156-157. [CrossRef]

21. Binder, K.; Ceperley, D.M.; Hansen, J.P.; Kalos, M.H.; Landau, D.P.; Levesque, D.; Weis, J.J. Monte Carlo Methods in Statistical Physics; Springer Science \& Business Media: Berlin/Heidelberg, Germany, 2012; Volume 7. 